\title{
One-stage posterior decompression and fusion using a Luque rod for occipito-cervical instability and neural compression
}

\author{
H-J Chen*,1, M-H Cheng ${ }^{1}$ and Y-C Lau ${ }^{2}$ \\ ${ }^{1}$ Department of Neurosurgery, Chang Gung University and Medical Center at Kaohsiung, Taiwan; ${ }^{2}$ Department of \\ Rehabilitation, Chang Gung University and Medical Center at Kaohsiung, Taiwan
}

\begin{abstract}
Study design: Original article.
Objective: The authors present seven cases who underwent one-stage suboccipital, $\mathrm{C} 1$ and/or $\mathrm{C} 2$ posterior decompression and fusion by Luque rod, wiring and autogenic bone graft for occipito-cervical instability and neural compression.

Setting: Chang Gung University and Medical Center at Kaohsiung, Taiwan.

Method: Since January 1996, 20 cases of craniovertebral and upper cervical spinal instability were encountered. Seven of these cases had no neurological improvment under Cone-Barton Skeletal traction. Imaging studies revealed poor reduction with persistent neural compression. One patient underwent unsuccessful anterior trans-oral vertebrectomy for decompression. All patients underwent posterior suboccipital craniectomy, $\mathrm{C} 1$ and/or $\mathrm{C} 2$ laminectomy for decompression. Contoured Luque rod with wiring and autogeneic bone graft was used for craniocervical fusion. After surgical treatment, halo-vest or sterno-occipito-mandibular immobilizer (SOMI) was used for 3-6 months

Results: Suboccipital craniectomy and C1 laminectomy could afford a $30-50 \%$ increment of anteroposterior diameter in the neural canal and effective decompression of the low medulla and cord. All patients made neurological improvement. The ASIA-MIS scores improved from pre-operative 49 (mean) to 78. Four patients can walk without any support. There were no major complications except for one case requiring readjustment of the halo-vest brace.

Conclusion: The authors recommend this procedure as one choice for relieving craniocervical instability with neurological compromise. A programmed rehabilitation will afford better neurological improvement.

Spinal Cord (2001) 39, $101-108$
\end{abstract}

Keywords: cervical spine; craniocervical junction; neural compression; posterior spinal decompression; posterior spinal instrumentation

\section{Introduction}

Occipitocervical instability is a life-threatening problem. The fixation procedures have always presented a big challenge to neurosurgeons. ${ }^{1-4}$ The anatomical structures in this area are very complex. The most critical element is the medulla and cord inside the bony and soft tissue structure. Any type of instrumentation must accommodate the anatomical structures and support the biomechanical needs of the craniovertebral junction. ${ }^{4-9}$ For a simple upper cervical instability such as a type II odontoid fracture with $\mathrm{C} 1-\mathrm{C} 2$ subluxation, we use wire securing techniques and then, a Halifax clamp with an autogenic bone graft. ${ }^{10-14}$ A highly successful fusion rate has been achieved in our 14 years of experience.

Wire-securing techniques, which secure the bony structure with suboccipital and sublaminar wires, has

*Correspondence: H-J Chen, 123, Ta-Pei Road, Niao-Sung Hsiang, Kaohsiung Hsien, Taiwan the advantage of low cost. Unfortunately, these techniques carry a very high risk for the patients who have nonreducible cranio-vertebral subluxation and signs of neurological structure compression. These techniques also often fail to provide a rigid fixation to promote long-term arthrosis. ${ }^{5,10,11,14-16}$ Other advancements such as the Halifax clamp, cannot provide a successful rigid cranio-cervical fixation. ${ }^{9}$ There are several newly developed instrumentations which have since provided a more rigid craniovertebral support, however, these plates or screws are not cost effective and practical in surgical treatment..$^{5,17-20}$

Besides cranio-vertebral axis fixation, decompression of the neural canal for neurological deficits is the other major task for neurosurgeons. Transoral ventral decompression is one of the considerations for neural decompression, ${ }^{21,22}$ however, the patients will endure more risks due to multiple surgical interventions and sometimes, adequate ventral decompression cannot be 
achieved. For simultaneous neural decompression and occipito-cervical fixation, we have developed a onestage posterior decompression and fusion technique with a contoured Luque rod, wiring and iliac bone graft for occipito-cervical instability and neural compression. ${ }^{9,23-26}$

\section{Methods}

\section{Patient population}

Between January 1996 and April 1999, 20 patients with cranio-vertebral and upper cervical spine instability were admitted and treated in our institute. In seven of these cases, occipito-cervical subluxation with neural compression was found. There were six men and one woman with a mean age of 54 years (range 42-77). The clinical characteristics of these patients, including the causes of lesions, neurological deficits according to the American Spinal Injury Association (ASIA) Motor Index Score (MIS) ${ }^{27}$ before and follow-up results after treatment are summarized in Table 1. Of these seven cases, cranio-vertebral instability was due to rheumatoid arthritis in one case, ankylosing spondylitis in one case, neglected cranio-cervical injury in two cases and traffic accidents in three cases.

All of the seven patients were treated according to the following protocol. Evaluation of haemodynamic and neurological conditions were performed. Resuscitation was given if necessary. Radiological examination including plain cranio-vertebral radiography, computed tomography (CT) through bone windows and magnetic resonance imaging (MRI) of the head and cervical spine were performed as soon as possible. Cone-Barton skull tongs were applied. The initial traction weight was $3 \mathrm{~kg}$ and gradually increased to $5 \mathrm{~kg}$. The patients were admitted to the intensive care unit for any respiratory distress. If follow-up X-rays revealed no further reduction, or the neurological status showed no improvement or even exacerbation, we took surgical treatment. A transoral approach for anterior vertebrectomy decompression was performed in one patient, who had ankylosing spondylitis. The neurological status became worse after this unsuccessful surgery. All patients underwent one-stage posterior decompression, including suboccipital craniectomy, $\mathrm{C} 1$ and/or $\mathrm{C} 2$ partial posterior arch laminectomy depending on the site of compression, contoured Luque rod with wiring in the suboccipital area, $\mathrm{C} 1$ and $\mathrm{C} 2$ or even $\mathrm{C} 3$ laminae and autogeneic iliac bone graft.

\section{Surgical technique}

For this procedure, the patient was under endotracheal general anaesthesia and Cone-Barton Skull Tong, changed to the prone position with gel cushions under the face, neck and chest on a rotary table. The alignment of the cranio-vertebral axis was monitored by fluoroscope. The patient's head and neck were shaved and prepared.

A median skin incision extended from the external occipital protuberance to $\mathrm{C} 4$. The nuchal ligament was divided and muscles were stripped from the bony attachment. A very gentle operative technique was used so as not to disturb the important anatomical structures. The muscles attached to the posterior arch of $\mathrm{C} 1$ and the spinous processes of $\mathrm{C} 2$ and $\mathrm{C} 3$ were gently swept laterally.

The dissection was continued laterally; injury was prevented to the horizontal segment of the vertebral artery and suboccipital venous structures. ${ }^{28,29}$ Bleeding from the veins was sometimes troublesome. It could be controlled with Gelfoam or Surgicel. The atlantooccipital membranes, ligamentum flavum, laminae and spinous processes were well exposed with curettes and dissectors. Suboccipital craniectomy, $\mathrm{Cl}$ and/or C2 limited laminectomy for decompression was performed according to preoperative image studies. Craniectomy and laminectomy were very carefully performed with microinstruments or even under the operative microscope. The size of the craniectomy or laminectomy was large enough for decompresssion and the margin of the bony edges were still inside the contoured Luque rod. The atlantoccipital membrane and ligamentum flavum in $\mathrm{C} 1$ and $\mathrm{C} 2$ were removed with microkerrison rongeurs. The decompression was achieved and good expansion of the thecal sac could be found. Two small drill holes were made bilaterally in the suboccipital area for wire passage and fixation. The

Table 1 History and outcome data in seven patients

\begin{tabular}{|c|c|c|c|c|c|c|}
\hline \multirow[b]{2}{*}{ Case no } & \multirow[b]{2}{*}{ Age } & \multirow[b]{2}{*}{ Sex } & \multirow[b]{2}{*}{ Cause of lesion } & \multicolumn{2}{|c|}{$A S I A-M I S$} & \multirow{2}{*}{$\begin{array}{l}\text { Follow-up period } \\
\text { (months) }\end{array}$} \\
\hline & & & & Pre-operative & Postoperative & \\
\hline 1 & 42 & M & Neglected trauma & 56 & 80 & 36 \\
\hline 2 & 47 & M & Ankylosing spondylitis & 38 & 88 & 30 \\
\hline 3 & 55 & $\mathrm{~F}$ & Rheumatoid arthritis & 40 & 62 (on wheel chair) & 24 \\
\hline 4 & 77 & M & Fall & 65 & 85 & 20 \\
\hline 5 & 50 & M & Traffic accident & 40 & 82 & 16 \\
\hline 6 & 52 & M & Traffic accident & 58 & 80 & 12 \\
\hline 7 & 55 & M & Neglected trauma & 48 & 67 & 7 \\
\hline
\end{tabular}


sublaminar wire was carefully passed through the laminar defect in $\mathrm{C} 1$ or $\mathrm{C} 2$ after laminectomy.

The angle and width of the contoured Luque rod should be precisely measured and made by a medical engineer before surgery. It could be intimately placed over the suboccipital area and the remainder of the $\mathrm{C} 1$ and C2 laminae. The wire was carefully, slowly twisted to avoid cutting through the cortical bone (Figure 1). Decortication of the outer cortex of the lateral masses was performed with a burr, and chips of local bone or monocortical iliac bone were grafted onto the lateral masses and fixed using the wire twist nodes. Cancellous bone from the same source was also grafted onto the lateral masses. Finally, the wound was closed in layers. The neural compression is usually due to a decrease in the anteroposterior diameter in spite of the transverse diameter. An effective laminectomy and excision of the ligamentum flavum in $\mathrm{C} 1$ or $\mathrm{C} 2$ will afford an additional $30 \%$ to $50 \%$ increment in the anteroposterior diameter of the spinal canal (Figure 2).

\section{Postoperative management}

Halo vests were used in five patients. A rigid SOMI external fixation was used in two patients. For bony union, these devices were worn for 3-6 months by the patients. They were regularly followed up in an outpatient clinic.

\section{Results}

Seven adults (aged 42-77 years) underwent posterior decompression in the suboccipital area, C1 and/or C2 laminectomy and fixation by Luque rod, wiring and iliac bone graft. The follow-up period ranged from 6 months to 3 years. We used ASIA-MIS for neurological evaluations before and after surgical treatment. The pre-operative neurological examination revealed that motor function in the upper limbs was better. The ASIA-MIS scores before surgery were from 38 to 70 (mean 49). The final scores after followup were from 62 to 88 (mean 78). The result is shown in Table 1. All cases in this series demonstrated neurological improvement after surgical treatment, even in Case 2 and 4 who presented severe preoperative neurological deficits. They could walk without crutches. All cases received follow-up rehabilitation.

None of these patients deteriorated after the procedures. No major complications developed. Readjustment of the halo vest was made one month after surgery in Case 5. The final result was good.

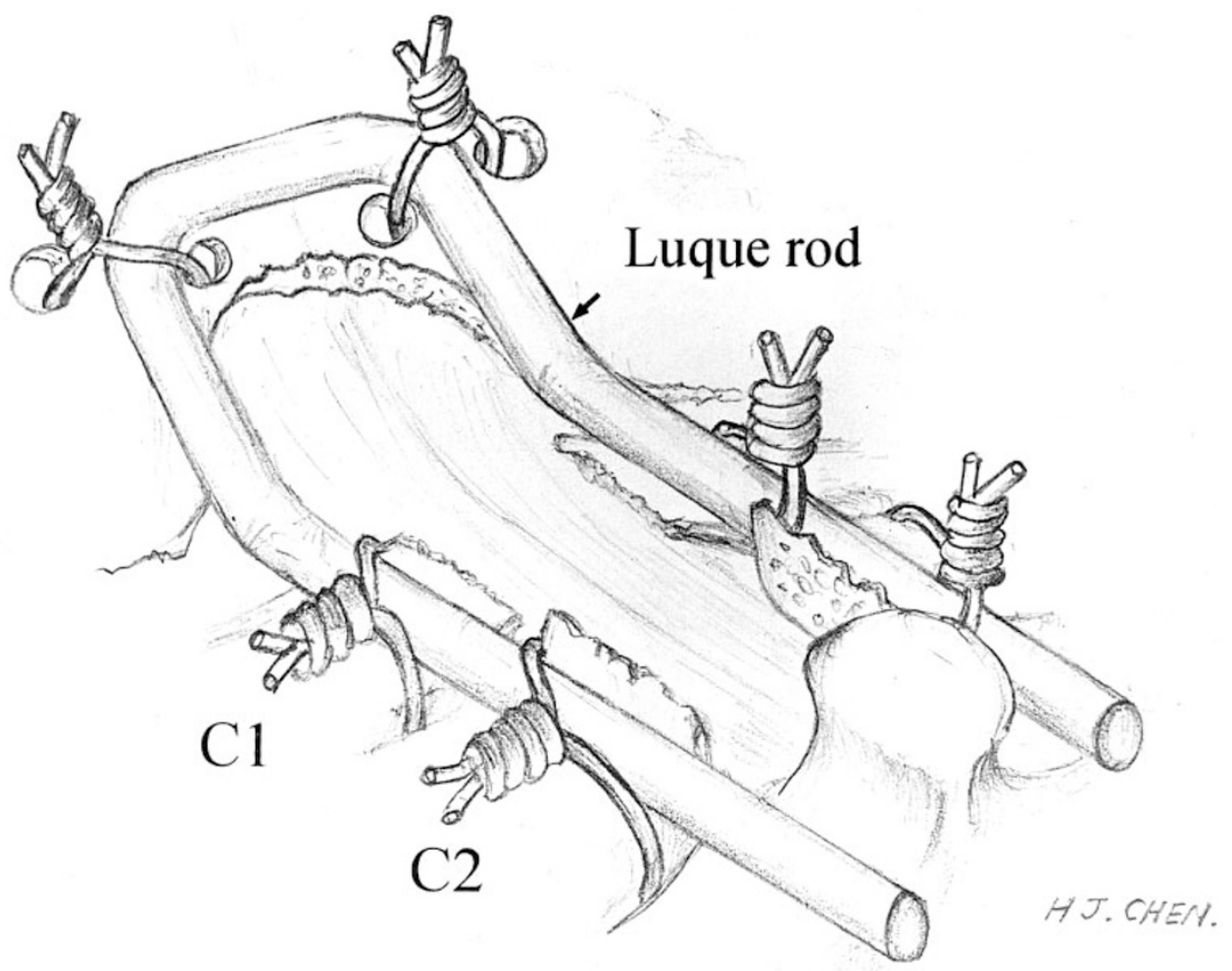

Figure 1 Illustration of craniectomy, C1 C2 laminectomy and Luque rod with wire fixation. The Luque rod can intimately contact the suboccipital bone and margin of the remainder $\mathrm{C} 2$ spinous process 


\section{Odontoid process}

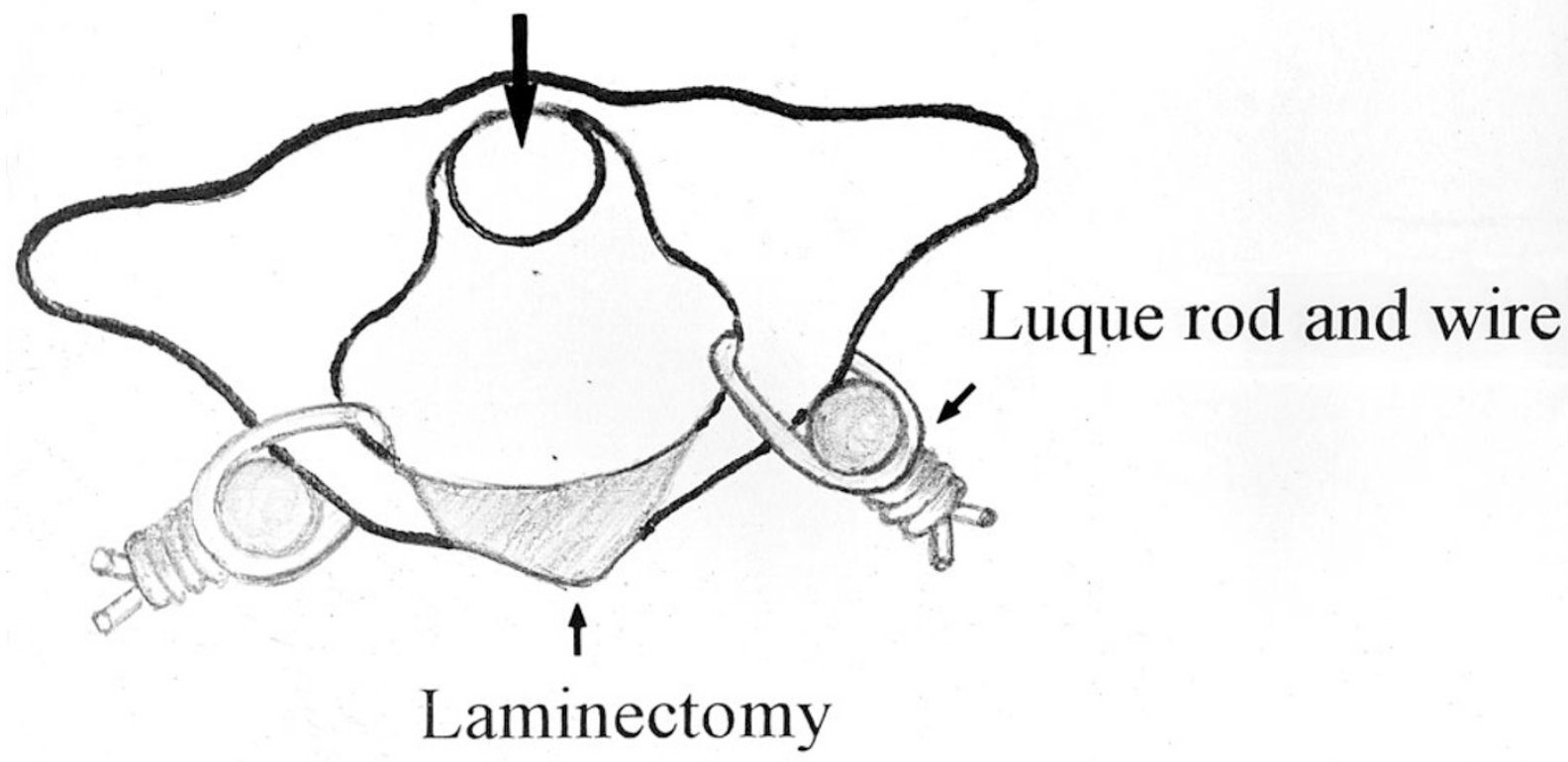

Figure 2 This is a sketch of the $\mathrm{C} 1$ bone window on CT in Case 6. The grayish area in the posterior arch demonstrates the laminectomy site. An effective increment in anteroposterior diameter after removal of the ligamentum flavum and lamina can be found

\section{Case illustrations}

Case 4

History A 77-year-old man was sent to the emergency room due to a fall downstairs. Neurological examination disclosed paraparesis. The ASIA-MIS score was 65. Numbness was noted on the lower limbs. Plain radiography revealed fracture of the odontoid process, $\mathrm{C} 1-\mathrm{C} 2$ subluxation and a narrow functional canal (Figure 3). MRI showed displacement in the occipito-cervical junction with cord compression (Figure 4).

He was put in Cone-Barton skull traction. Within the first week, he made no improvement in motor function and sensation. Follow-up cervical plain Xray showed that subluxation of $\mathrm{C} 1-\mathrm{C} 2$ remained. $\mathrm{He}$ underwent surgical treatment as described above. During surgery a fracture of the posterior $\mathrm{Cl}$ arch was found. Posterior decompression in the foramen magnum was made. Intra-operative fluoroscope revealed acceptable subluxation reduction. Contoured Luque rod with a precise angle was placed and fixed with wiring on the suboccipital area, C2 and C3 laminae. The fractured $\mathrm{Cl}$ posterior arch was replaced and an iliac bone graft was put on the lateral masses.

Postoperative course Improvement of lower limb strength was noted within the first post-operative week. A halo vest was used the third day after

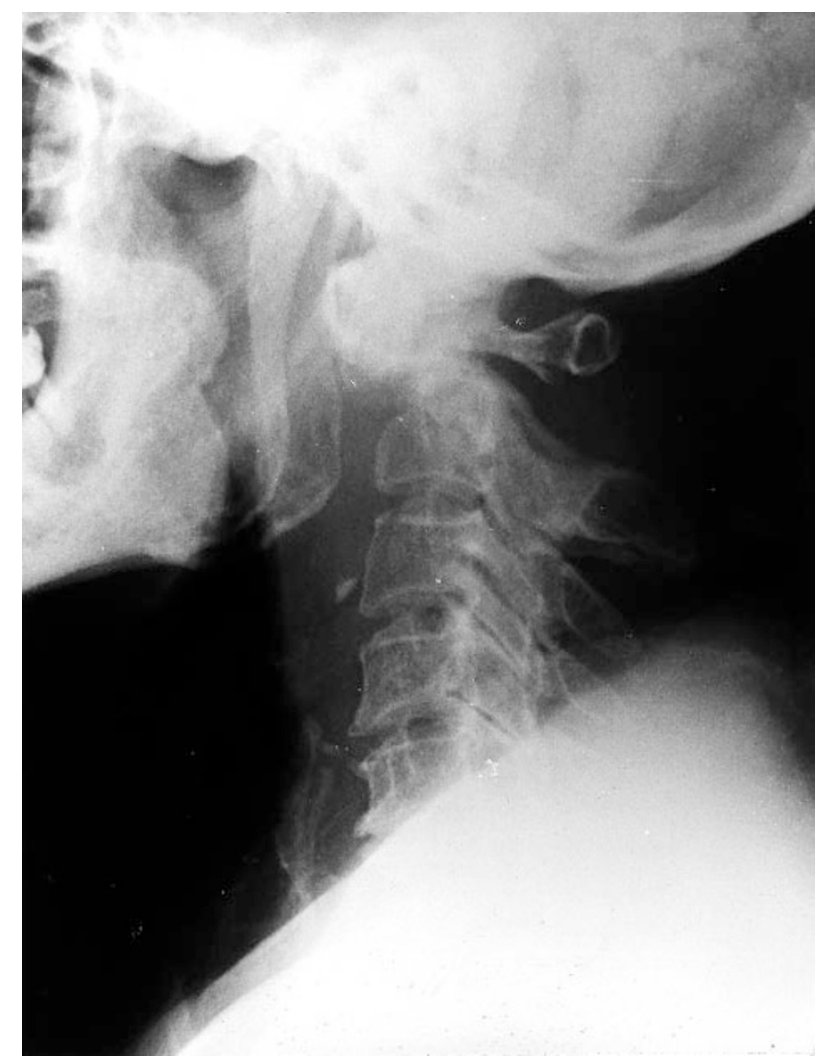

Figure 3 Plain X-ray film of Case 4 on admission revealed fracture of the odontoid process, C1-C2 subluxation and narrow functional thecal canal in the foramen magnum and C1 level 


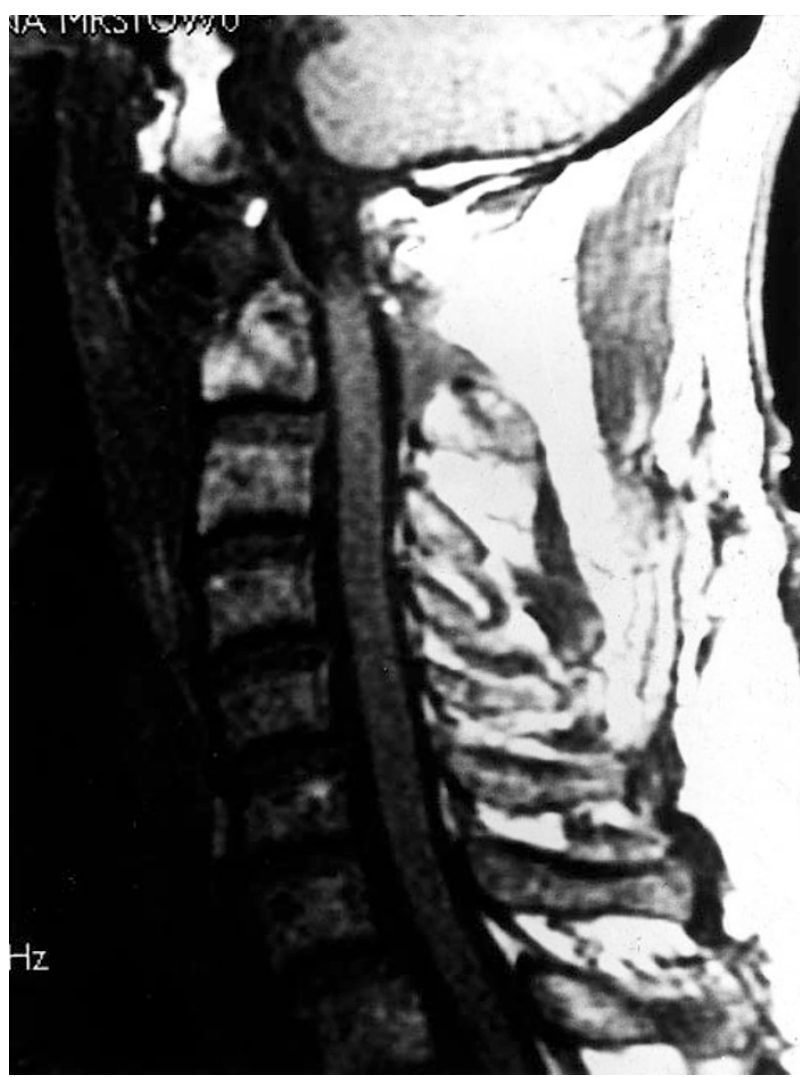

Figure 4 MRI study (T1-weighted image) of Case 4 revealed compression of the lower medulla and upper cervical cord

surgery. He received subsequent programmed rehabilitation. The halo vest was removed 6 months after surgery and the internal instruments were in proper position (Figure 5). He could walk smoothly without any support.

\section{Case 7}

History A 55-year-old man suffered a falling injury at the age of 10. The initial symptom was neck pain without any neurological deficit. Spastic gait with weakness in the left lower limb developed after adolescence. The neurological deterioration slowly progressed and he was confined to a wheelchair. Neurological examination disclosed near paraplegia. The muscle strength in the right upper limb was still good but fair on the left side. Hyper-reflexia with clonus was noted. Plain radiography revealed a neglected odontoid fracture and $\mathrm{C} 1-\mathrm{C} 2$ subluxation. MRI showed significant occipito-cervical deformity and cord compression (Figure 6).

$\mathrm{He}$ was put in Cone-Barton skull traction for reduction. He made no improvement in his motor function. Follow-up X-ray studies revealed no improvement in the occipitocervical alignment.

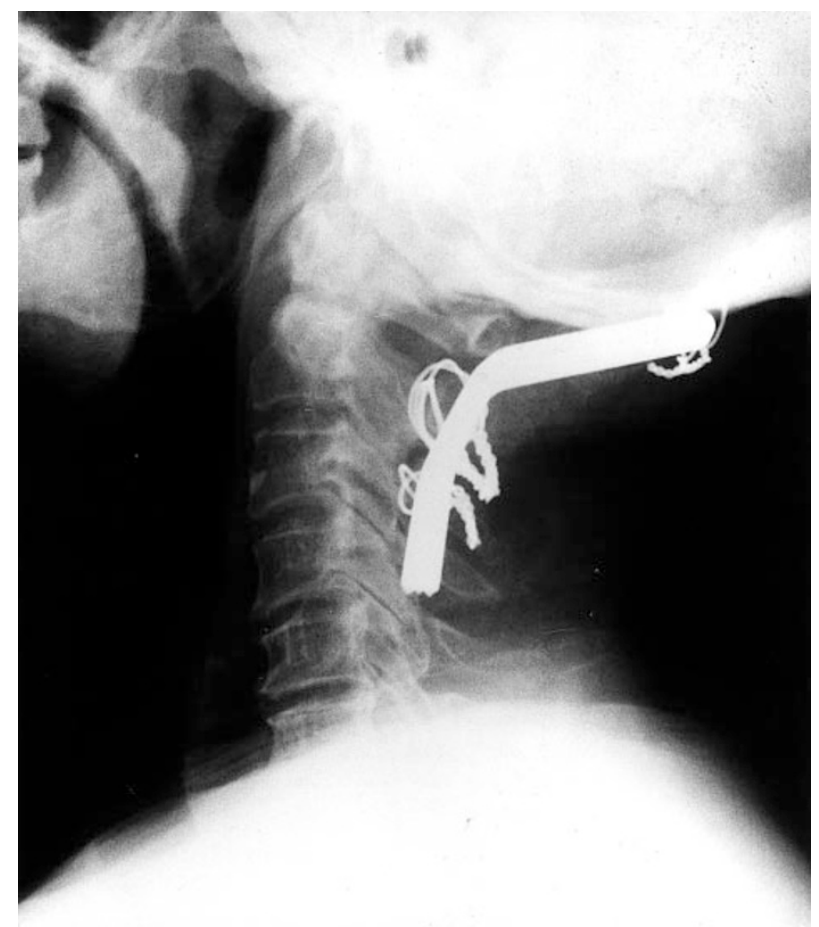

Figure 5 Follow-up plain X-ray film of Case 4 (6 months after surgery) reveals good alignment of the cranio-vertebral junction

Operation The patient was placed under very meticulous endoscopic transnasal endotracheal general anaesthesia and put in a prone position on a rotary table. The occipito-cervical axis was kept in the lordotic position and verified by fluoroscope. Very gentle operative techniques were used so as not to disturb important anatomical structures. The suboccipito-C1 venous structure was very prominent. The venous bleeding was controlled with Surgicel. For decompresssion, a high-speed burr drill was used for a limited laminectomy in $\mathrm{C} 1$ and $\mathrm{C} 2$. The inner table of the C1-C2 laminae was removed with a micro-kerrison rongeur and the ligamentum flavum was excised with micro-scissors. The thecal sac demonstrated good pulsation after decompression. A precisely contoured Luque rod was placed on the suboccipital region and the remaining $\mathrm{C} 1$ and $\mathrm{C} 2$ laminae and fixed onto the bony structure with wiring. A monocortical iliac bone graft with cancellous bone was placed laterally and fixed with wire twist nodes.

Postoperative course A SOMI brace was worn the third day after surgery. Subsequently, he made slow progress regarding motor and sensory functions. $\mathrm{He}$ could walk with a walker 3 months later. Though the gait spasticity remained, he could walk more smoothly 6 months postoperatively. Follow-up cervical plain Xray revealed proper instrumentation location (Figure 7). 


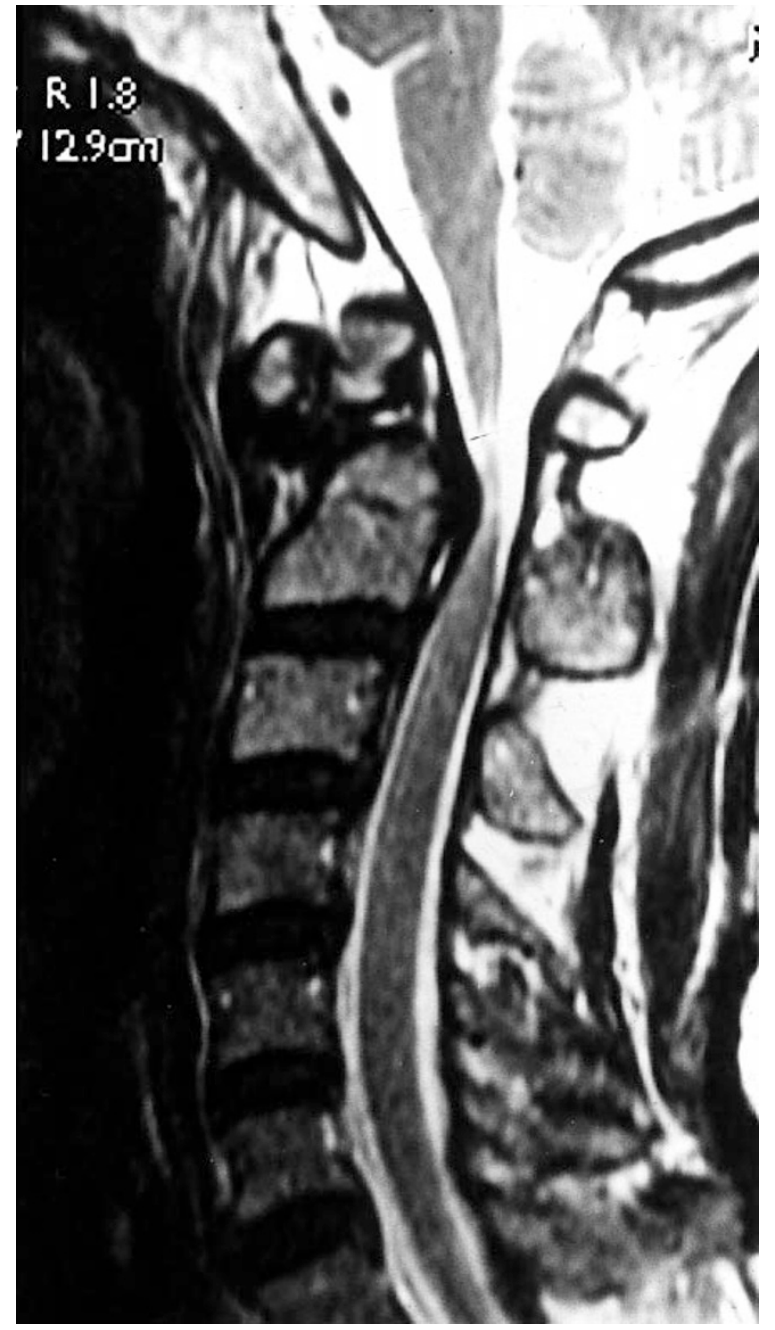

Figure 6 MRI studies in Case 7 before treatment reveals odontoid fracture and $\mathrm{C} 1-\mathrm{C} 2$ subluxation. The cord compression in the $\mathrm{C} 1$ and $\mathrm{C} 2$ segment is also seen

\section{Discussion}

Occipito-cervical instability may be caused by tumour (benign or malignant), trauma, inflammation, congenital anomalies or degenerative diseases and is usually associated with severe medullo-cord injury and neurological deficit. ${ }^{1,8,11,15,28,30,31}$ Because of improvements in radiological diagnosis, these pathological abnormalities are now identified earlier.

The management of the cranio-vertebral junction, including upper cervical spinal injuries, depends on surgical treatment for certain patients. In general, surgical therapy is recommended when medical or other supportive treatment is not appropriate or applicable. The goal of surgical treatment in this region is not only for re-alignment of the vertebral column. ${ }^{18,19}$ The very important surgical achievements are neural structure decompression and fusion of the

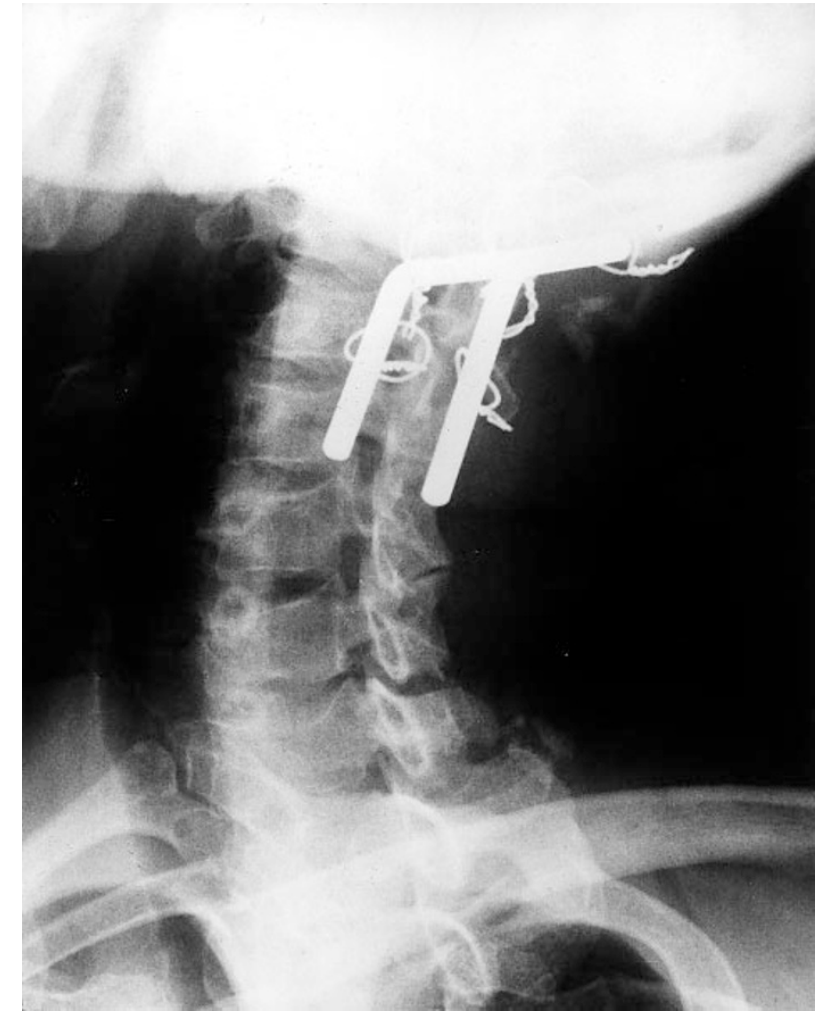

Figure 7 Follow-up plain X-ray (right oblique view) reveals internal instrumentation in Case 7 ( 5 months after surgery). The Luque rod was fixed with wire in the suboccipital area, $\mathrm{C} 1$ remainder posterior arch and the $\mathrm{C} 2$ and $\mathrm{C} 3$ spinous processes. The autogeneic iliac bone graft is visible (arrow)

complex, hypermobile cranio-vertebral junction, without permanent immobilization and arthrodesis of the non-injured, physiologically normal, adjacent vertebral column. ${ }^{8,1819}$

Before using one-stage posterior decompression and Luque rod, wire and bone graft fixation, ventral decompression through the transoral approach was made for ventral brainstem or spinal cord compression. $^{2,21,22}$ Because achieving internal fixation and fusion is difficult in patients requiring decompression in the low clivus and upper cervical spine, these patients usually need posterior stabilization and fusion in addition to ventral decompression.

For properly selected cases, the ventral approach is one of operative choices for neural decompression. The authors met a bitter experience in the management of Case 2. This 47-year-old man had a long-term history of ankylosing spondylitis and was admitted in a wheelchair. The MRI studies revealed marked deformity in the cranio-vertebral junction (Figure 8). Ventral decompression through the transoral approach was performed. Because of rigidity in the craniovertebral axis, the surgical treatment could not achieve an adequate decompression and he experienced motor function deterioration. Paraplegia and respiratory 


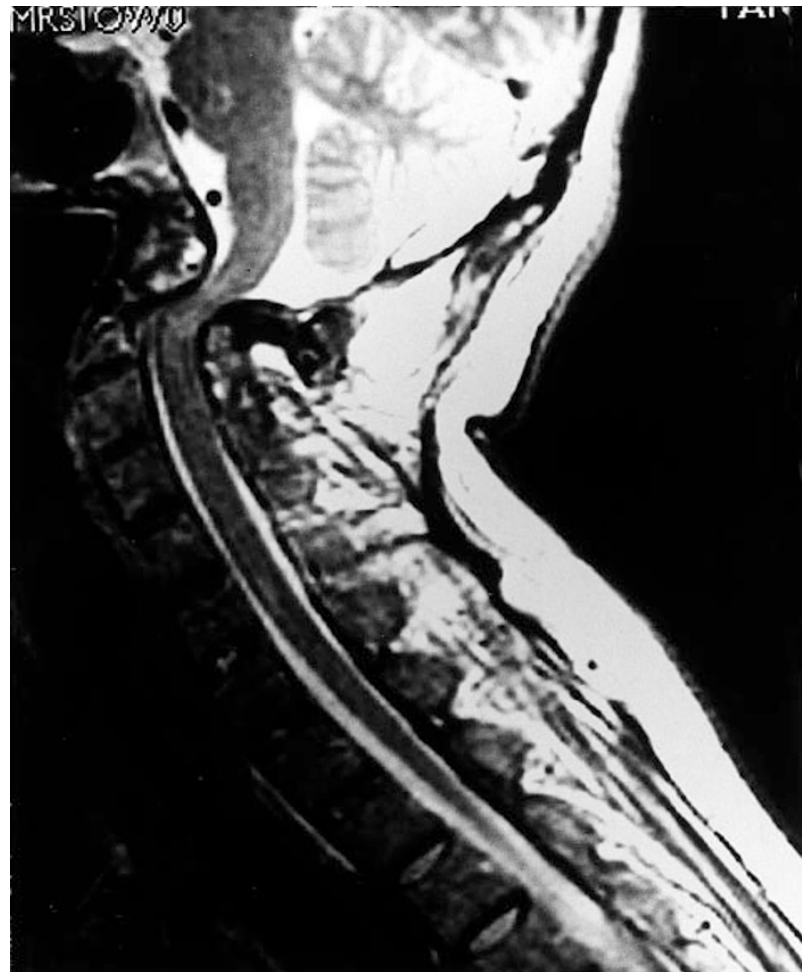

Figure 8 Preoperative MRI study in Case 2 reveals deformity in the cranio-vertebral junction and neural compression due to ankylosing spondylitis

distress developed within the first post-operative week. An effective posterior decompression in the occiput, $\mathrm{C} 1$ and $\mathrm{C} 2$ with Luque rod internal fixation was performed. A SOMI brace was used for the following rehabilitation period. He made a smooth recovery and could walk with support 3 months later.

The authors have experience with more than 50 cases involving wire-securing procedures or Halifax clamp to treat $\mathrm{C} 1-\mathrm{C} 2$ subluxation. However, these kinds of internal fixation are not effective for occipitocervical instability. ${ }^{4,5,8,9,14,18,32}$ Dorsal cervical spinal internal fixation can be accomplished with several designs of plates and screws. These instruments can be extended superiorly to $\mathrm{C} 1$ or even the occiput, with appropriate screw fixation at the upper cervical spine and the skull base with good results demonstrated. We chose the Luque rod. ${ }^{24}$ The medical engineer can make a very precise Luque rod angle for the craniovertebral axis. The width of the Luque rod rectangle can be made with a tight fixation to the margin of the spinous processes. ${ }^{25,26}$ The wire can be safely passed into the sublaminal space through the laminectomy. It is also very cost effective. We experienced no major complications, except one of broken wire of the $\mathrm{C} 2$ level. This patient made a smooth recovery. For the reason of cost, the wire and contoured Luque rods in these seven cases were all stainless steel. Now, we have changed to the use of
MR compatible titanium material and soft wire. These new materials afford good follow-up images and safer surgical manipulation during sublaminar passage of wires.

With the application of internal fixation hardware and iliac bone graft for long-term success and healing, the halo vest or other rigid braces are used for the following 6 months. All patients showed neurological improvement in the follow-up period. Four patients could walk without any support. Compared with other reports, the results are acceptable, though this report is a small series. Because wire or cables may easily pull or cut through the thin occipital bone or posterior arches of the upper cervical spine, we do not consider children as candidates for this kind of surgical treatment.

\section{Conclusion}

This report provides our preliminary experience with one-stage posterior decompression and fusion with Luque rod, wiring and bone graft for occipito-vertebral instability and neural compression. All patients presented postoperative neurological improvement after programmed rehabilitation. Four patients can walk without support. There were no major complications encountered with this procedure. This series is small; however, the results were acceptable. The authors conclude that this kind of surgical treatment and post-operative programmed rehabilitation is effective for cranio-vertebral fixation and neurological recovery.

\section{References}

1 Bucholz RW, Burkhead WZ. The pathological anatomy of fatal atlanto-occipital dislocations. Am J Bone Joint Surg 1979; 61: $248-250$.

2 Hadley MN, Sonntag VK. Acute axis fractures. Contemp Neurosurg 1987; 71: $642-647$.

3 Papadopoulos SM et al. Traumatic atlanto-occipital dislocation with survival. Neurosurgery 1991; 28: 574-579.

4 Wertheim SB, Bohlman HH. Occipitocervical fusion: indications, technique, and long-term results in thirteen patients. $J$ Bone Joint Surg (Am) 1987; 69: 833-836.

5 Grantham SA, Dick HM, Thompson RC Jr, Stinchfield FE. Occipitocervical arthrodesis: indications, technique, and results. Clin Orthop 1969; 65: $118-129$.

6 Hamblen DL. Occipito-cervical fusion: indications, technique, and results. J Bone Joint Surg 1967; 49: $33-45$.

7 Panjabi M et al. Three-dimensional movements of the upper cervical spine. Spine 1988; 13; 726-730.

8 Sonntag VK, Dickman CA. Craniocervical stabilization. Clin Neurosurg 1993; 40: $243-272$.

9 Sonntag VK, Dickman CA. Occipitocervical instrumentation. In Hitchon PW, Traynelis VC, Rengachary SS (eds). Techniques in spinal fusion and stabilization. Thieme: New York, 1995, pp $107-$ 121

10 Brattstrom H. Surgery in atlanto-axial dislocation in rheumatoid arthritis. Reconstr Surg Traumatol 1981; 18: 16-29.

11 Cregan JC. Internal fixation of the unstable rheumatoid cervical spine. Ann Rheum Dis 1966; 25: 242-252.

12 Dickman CA, Sonntag VK, Marcotte PJ. Techniques of screw fixation of the cervical spine. BNI Quart 1992; 8: 9-26. 
13 Dunn EJ, Anas PP. The management of tumors of the upper cervical spine. Orthop Clin North Am 1978; 9: 1065 - 1080.

14 Statham P, O'Sullivan M, Russell T. The Halifax interlaminar clamp for posterior cervical fusion: initial experience in the United Kingdom. Neurosurgery 1993; 32: 396-399.

15 Crockard HA et al. Surgical treatment of cervical cord compression in rheumatoid arthritis. Ann Rheum Dis 1985; 44: $809-816$.

16 Fehlings MG et al. Occipitocervical fusion with a five-millimeter malleable rod and segmental fixation. Neurosurgery 1993; 32: $198-207$.

17 Ellis PM, Findlay JM. Craniocervical fusion with contoured Luque rod and autogeneic bone graft. Can J Surg 1994; 37: 50 54.

18 Grob D. Biomechanical evaluation of four different posterior atlantoaxial fixation techniques. Spine 1992; 17: 480 - 489.

19 Grob D. Posterior occipitocervical fusion. A preliminary report of a new technique. Spine 1991; 16: $517-524$.

20 Heywood AW, Learmonth ID, Thomas M. Internal fixation for occipito-cervical fusion. Br J Bone Joint Surg 1988; 70: 708 - 711.

21 Geisler FH, Cheng C, Poka A, Brumbak RJ. Anterior screw fixation of Posteriorly displaced type II odontoid fractures. Neurosurgery $1989 ; \mathbf{2 5} ; 34-38$.

22 Menezes AH, VanGilder JC. Transoral-transpharyngeal approach to the Anterior craniocervical junction: ten-year experience with 72 patients. J Neurosurg 1988; 69: 895-903.
23 Luque ER. The anatomic basis and development of segmental spinal instrumentation. Spine 1982; 7: 270-275.

24 Luque ER. Interpeduncular segmental fixation. Clin Orthop 1986; 203: $54-57$.

25 MacKenzie AI, Uttley D, Marsh HT, Bell BA. Craniocervical stabilization using Luque/Hartshill rectangles. Neurosurgery 1990; 26: $32-36$.

26 Ransford AO et al. Craniocervical instability treated by contoured loop fixation. Br J Bone Joint Surg 1986; 68: 173-177.

27 Lucas JT, Ducker TB. Motor classification of spinal cord injuries with mobility, morbidity and recovery indices. Am Surg 1979; 45: $151-158$

28 Al-Mefty $\mathrm{O}$ et al. The transcondylar approach to extradural nonneoplastic lesions of the craniovertebral junction. $J$ Neurosurg 1996; 84: $1-6$

29 Arnautovic KI et al. The suboccipital cavernous sinus. $J$ Neurosurg 1997; 86: $252-262$.

30 Harrington KD. Current concepts review. Metastatic disease of the spine. Am J Bone Joint Surg 1986; 68: 1110-1115.

31 Itoh $\mathrm{T}$ et al. Occipito-cervical fusion reinforced by Luque's segmental spinal instrumentation for rheumatoid diseases. Spine 1988; 13: $1234-1238$

32 Fielding JW, Hawkins RJ, Ratzan SA. Spine fusion for atlantoaxial instability. Am J Bone Joint Surg 1976; 58: 400-407. 